This item was submitted to Loughborough's Research Repository by the author.

Items in Figshare are protected by copyright, with all rights reserved, unless otherwise indicated.

\title{
Process capability models for equipment selection
}

PLEASE CITE THE PUBLISHED VERSION

PUBLISHER

(c) Taylor and Francis

VERSION

AM (Accepted Manuscript)

LICENCE

CC BY-NC-ND 4.0

REPOSITORY RECORD

Gindy, N., T.M. Ratchev, and Keith Case. 2019. "Process Capability Models for Equipment Selection". figshare. https://hdl.handle.net/2134/13680. 
This item was submitted to Loughborough's Institutional Repository (https://dspace.lboro.ac.uk/) by the author and is made available under the following Creative Commons Licence conditions.

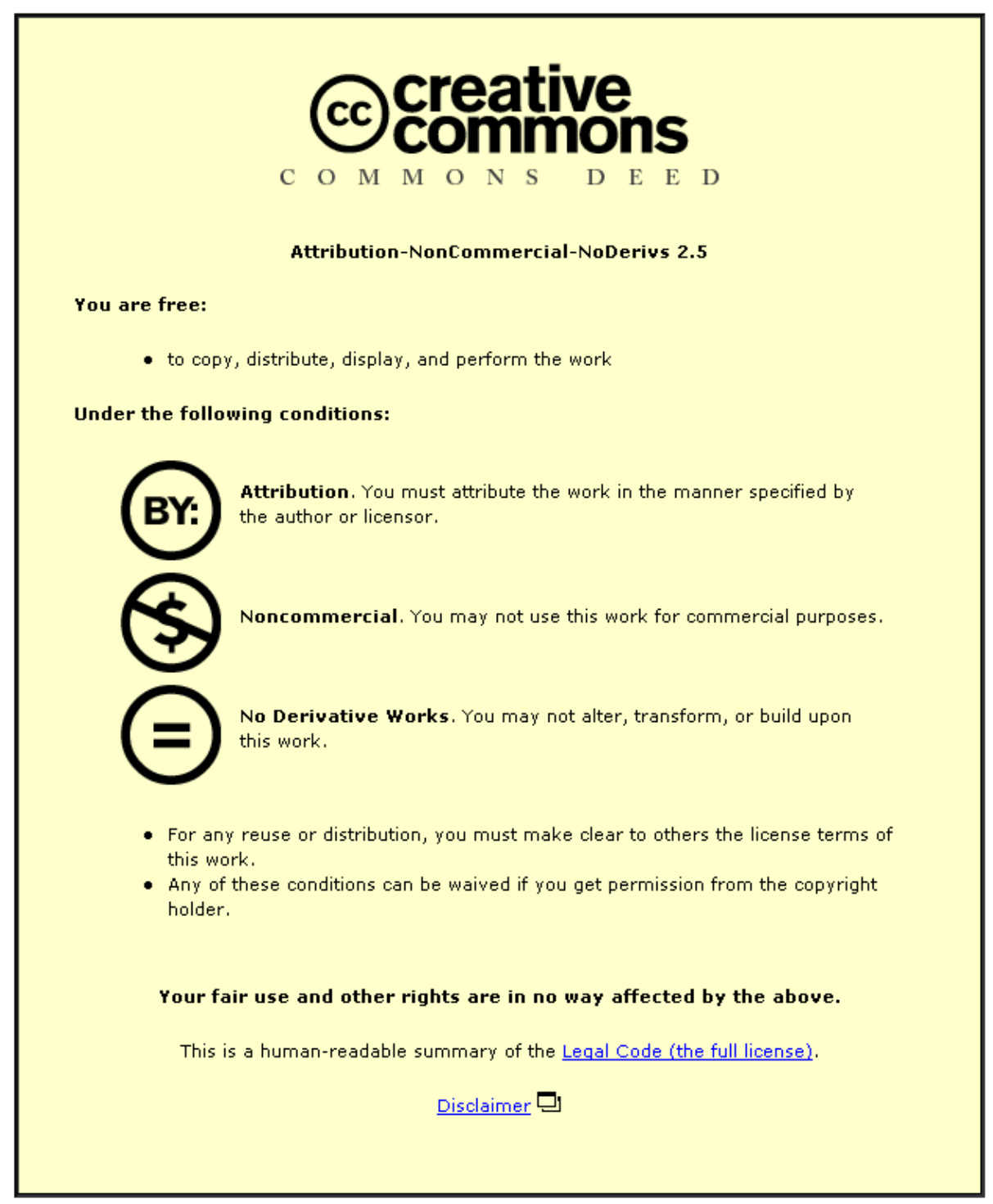

For the full text of this licence, please go to: http://creativecommons.org/licenses/by-nc-nd/2.5/ 
Gindy, N.N.Z., Ratchev, T.M. and Case, K. (1994).

Process capability models for equipment selection.

In K. Case, \& S. T. Newman (Eds.), 'Advances in Manufacturing Technology VIII', the Proceedings of the Tenth National Conference on Manufacturing Research, NCMR 1994 (pp. 244-248). Loughborough University of Technology, Loughborough, UK: London, UK, 5-7 September 1994: Taylor \& Francis.

\author{
PROCESS CAPABILITY MODELS FOR EQUIPMENT \\ SELECTION \\ Nabil N Z Gindy*, Tsvetan M Ratchev**, Keith Case** \\ *Department of Manufacturing Engineering and Operations \\ Management, University of Nottingham, Nottingham, NG7 2RD \\ **Department of Manufacturing Engineering, Loughborough \\ University of Technology, Loughborough, LE11 3TU
}

\begin{abstract}
Due to the increased complexity of modern manufacturing facilities and the increased demands for product variability and system flexibility there is a need for coherent formal representation of the basic knowledge domains supporting manufacturing applications such as equipment selection. The paper presents integrated framework for equipment selection based upon describing process capability at generic, machine tool and manufacturing system levels. The decision making process is designed as a sequence of steps for transforming component design information into processing requirements which are mapped into specific physical machines organised as a processing system.
\end{abstract}

\title{
1. Introduction
}

Equipment selection is a complex and time consuming process which requires a number of important decisions to be made and a large number of inter-related factors to be taken into account (Kochhar and Pegler, 1991). Many of the difficulties faced when attempting to formalise the decision making logic for equipment selection arise from the need to transform information, at several levels, between closely inter-related domains of components, manufacturing processes and manufacturing resources used for their production. Knowledge integration to facilitate transformations between the three domains is one of the crucial issues to be addressed during development of equipment selection systems.

The concept of using features for CAD/CAM applications has demonstrated significant potential during the recent years (Shah, 1992). Features, treated as generic entities for describing component attributes, act as basic information carriers during component design and machine selection. By attaching geometric as well as technological attributes to the features, main-stream activities such as process selection can be directed at a feature level.

Several approaches have been used to describe manufacturing processes and their 
capabilities (Alting, 1982; Eversheim, Marczinski and Cremner, 1991) Manufacturing processes were traditionally closely associated with specific types of machine tools used for their execution. The advent of multi-axis machining centres and the general increase in capabilities of machine tools, however, has reduced the relevance of such close linking and has underlined the need of machine independent process representation which can capture the exclusive and the repeated processing capabilities of different machine tools.

The approach adopted in this work is to relate process capability to three fundamental levels. The first is "form generating schema" to be used for describing process knowledge at a level that is independent of the machine tool and machining facility used for process execution. The second level of abstraction is the "operation" level that is used to attach machine specific attributes to manufacturing processes. The third is the "resource element" level which is used to complete the loop by relating both the form generating schema and operation levels to the way in which machine tools are organised as a manufacturing system.

The integrated model used as decision making support system for equipment selection is shown in Figure 1. The following sections of this paper give a brief overview of the model entities and equipment selection methodology adopted in this work.

\section{Component Data Model}

The input to the system is a feature based component description. Component features are considered as geometric entities which have significance in the context of component design and manufacture. Examples of such features are hole, step, pocket, etc., each of which is uniquely classified and described within a component model.

Features are treated as volumes enveloped by entry/exit and depth boundaries. Feature geometry is described by deciding on its external approach directions, i.e. the number of imaginary faces included in feature definition, its form variation with respect to its depth axis. Component form features are organised into a hierarchical structure for their definition and classification which includes categories, classes and sub-classes (Gindy, 1989).

Component connectivity which describes the relationships between adjacent features is represented by two types of links: external access directions for relating individual features to the basic component directions; and inheritance links that relate adjacent features, with some features becoming parents to other features (Gindy, Huang and Ratchev, 1993). At the component level, the technological relationships (geometrical and positional tolerances) between features are also recorded.

\section{Process Capability Models}

Process capability knowledge used for equipment selection is described at three basic levels: form generating schemas, machining operations and resource elements.

\subsection{Form Generating Schemas}

Form generating schema (FGS) is defined as technologically meaningful combinations of tool of specific geometry, sets of relative motions between a part and the tool, and nominal levels of technological output that can be associated with using that combination of tool and relative motions (see Figure 2). Form generating schemas are machine independent, but can be used to provide a generalised description of machine tool capabilities.

The links between the form generating schemas and the component features are provided through feature transition diagrams (FTD)-collections of form generating schemas capable of producing specific feature geometry and various levels of technological output. Feature transition diagrams reflect company specific knowledge on how features are machined.

Process selection is based on finding the set of terminal nodes in a feature transition diagram which match the feature requirements in terms of surface finish and tolerances. All 
feasible, equally weighted processing sequences are then selected through backtracking.

3.2 Machining operations

A form generating schema acts as the root for defining various machining

operations. Operation inherits the attributes of the FGS it originated from and the division

of motions between a part and the cutting tool from the machine tool used for its 


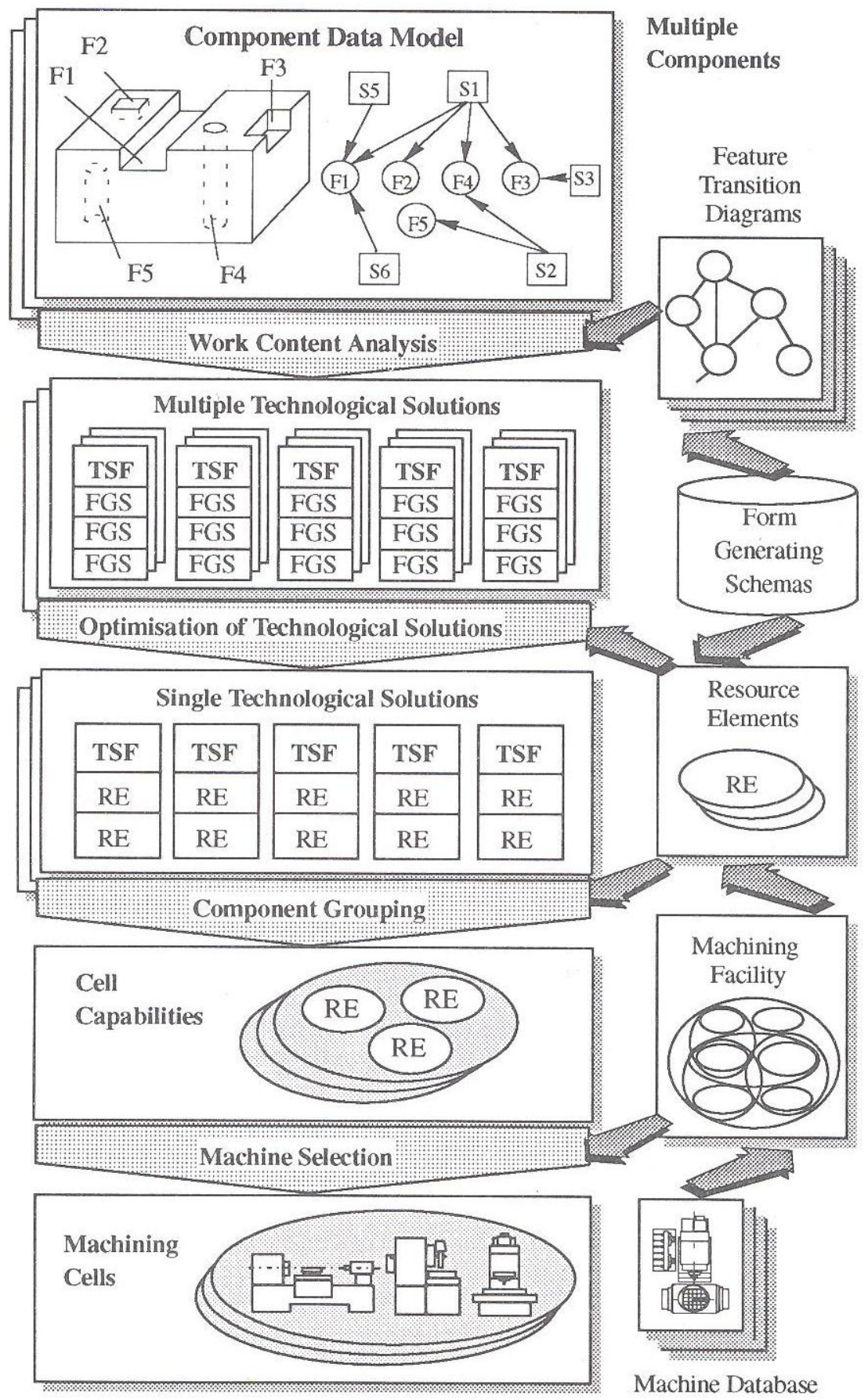

Figure 1. Equipment selection system - an overview 
execution. A machine tool performing an operation also provides the specific levels of technological output to be attached to machining operations.

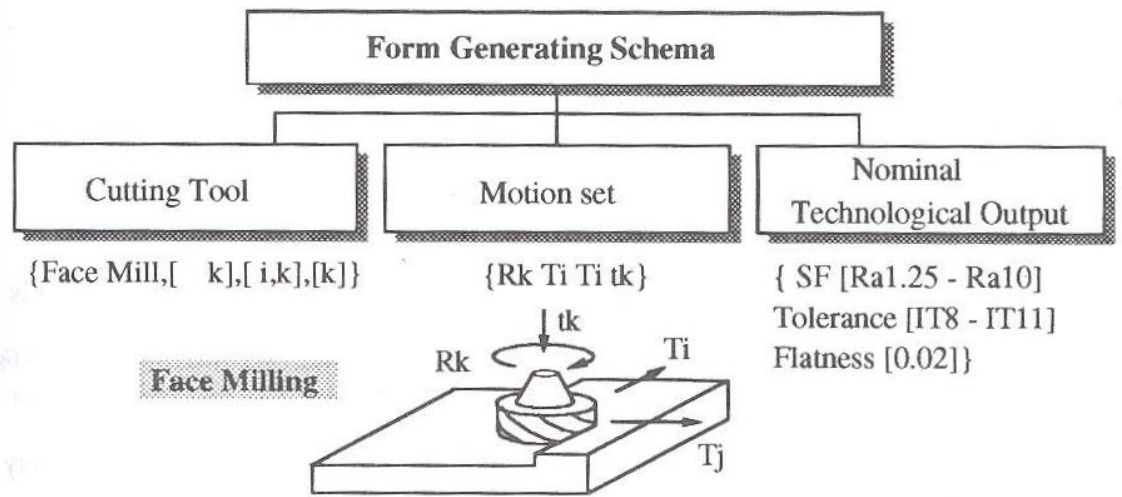

Figure 2. Form generating schema - an example.

A typical example are the machining operations originated from FGS "drilling" when performed on a lathe and on a drilling machine - their tool and motion set are identical with the only difference being that on a lathe component is rotating and the tool is translating while on a drilling machine both motions are given to the tool.

\subsection{Resource Elements}

Many manufacturing facilities contain identical machines and several machine tools with overlapping capabilities in terms of form generation and technological output. During equipment selection, however, a methodology is needed for comparing machine capabilities to provide a basis for deciding between alternatives before a final selection is made.

The set of machine tools defining a manufacturing facility are described using a set of resource elements (RE). Each RE represents a collection of form generating schemas which define uniquely the exclusive machine tool capability boundary and the shared boundaries between machine tools (see Figure 3).

Resource elements are machining facility specific and capture information relating to the distribution (commonality and uniqueness) of form generating schemas among the machine tools included in the machining facility.

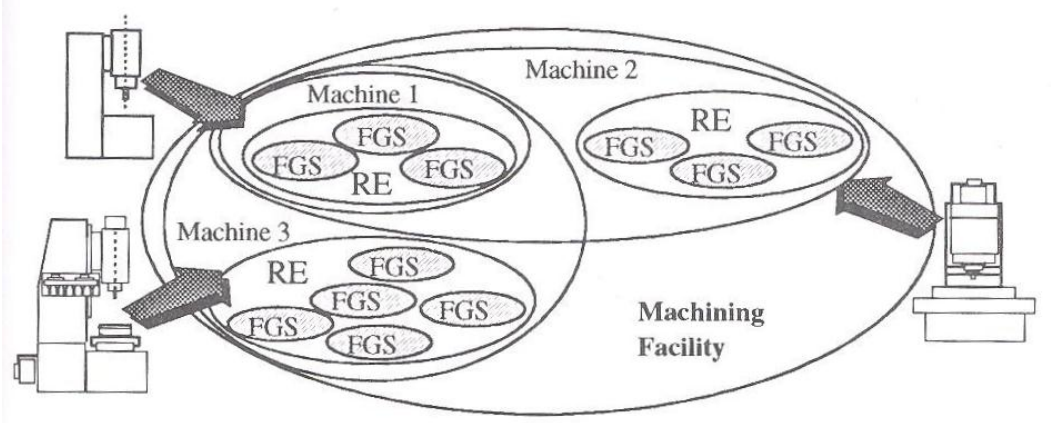

Figure 3. Machining facility represented using resource elements. 
Although an RE may be attached to several machine tools, a form generating schema can belong only to one RE. A machine tool has to be capable of carrying out all the form generating schemas of the REs associated with it.

\section{Prototype System for Equipment Selection}

Process capability models provided the basis for an integrated framework for equipment selection and cell determination described in Figure 1.

The selection procedure starts with a work content analysis module. Based on individual feature attributes, an FTD database is consulted and alternative TSFs (technological solutions at feature level) generated for each component feature of the target component set.

Deciding between alternative technological solutions for the component features is resource based. Each TSF is represented by a set of resource elements needed for its completion. The chosen optimisation strategy is based on selecting a combination of TSFs for the individual component features, such that variety of the resource elements used for processing the whole component set to be minimised. The result is a single TSF being attached to each component feature without pre-judging the set of machine tools that may be finally selected.

The capability requirements for each machining cell are first defined by component grouping using resource elements as basic grouping primitive. Grouping approach is based on fuzzy clustering with cluster validation (Gindy, Ratchev, 1993). The cell capability is defined by the sets of REs required by each component group.

The final step of the selection process is machine specification in terms of transforming the capability requirements of the designed machining cells into physical machines. The selection is carried out based exclusively on capability requirements without considering planning and scheduling issues at this stage.

\section{Conclusions}

The concept of resource elements is proving useful in providing a common basis for decision making throughout the machine selection and cell determination process. Resource elements provide flexibility in comparing the capabilities of individual machine tools and describing the processing capabilities of manufacturing facilities/cells.

Adopting modelling approach to integrating the information requirements of an application such as equipment selection has many advantages. The developed models help simplify the decision making logic and facilitate development of structured and modular systems which are easy to update and maintain.

\section{References} York).

Alting, L., 1982, Manufacturing Engineering Processes, (Marcel Dekker Inc., New

Eversheim, W., Marczinski, G., Cremner, R., 1991, Structured Modelling of Manufacturing Processes as NC-Data Preparation, Annals of CIRP, 40/1, 429-432.

Gindy, N.N.Z., 1989, A hierarchical structure for form features, Int. J. of Prod. Res., 27, 2089-2103.

Gindy, N.N.Z., Ratchev, T.M., 1993, Fuzzy based grouping methodology for component and machine grouping using resource elements, Report, ACME Grant GR/G35657, Loughborough University of Technology.

Gindy, N. N. Z., Huang, X., Ratchev, T. M., 1993, Feature-based component model for computer aided process planning systems, Int. J. of Computer Integrated Manufacturing, 6, 20-26.

Kochhar, A K., Pegler, H., A rule based systems approach to the design of manufacturing cells, Annals of CIRP, 40/1, 139- 142.

Shah, J.J., 1992, Features in Design and Manufacturing, in A Kusiak (ed.), Intelligent Design and Manufacturing, (J Wiley \& Sons, New York), 39-72. 